\title{
Factors Associated with High Blood Pressure in People Living with HIV at the National Teaching Hospital Hubert Koutoukou Maga and Cotonou Teaching Hospital of the Armed Forces
}

\author{
Azon Kouanou Angèle1* , Ayihounton Gaël2, Derrick Mémoire Dégbo², \\ Agbodande Kouessi Anthelme1, Sokadjo Yves Morel1, Missiho Mahoutin Semassa Ghislain1, \\ Faladé Adélakoun Ange Géoffroy ${ }^{1}$, Zannou Djimon Marcel'1, Houngbé Fabien ${ }^{1}$ \\ ${ }^{1}$ Internal Medicine-Medical Oncology Unity of the National Teaching Hospital Center (NTHC)-Hubert Kougougou Maga (HKM) \\ of Cotonou, Cotonou, Benin \\ ${ }^{2}$ National Reference Center for Research and Care (CNRRPEC) of HIV Infection, Cotonou, Benin \\ Email: *angele.azonkouanou@gmail.com
}

How to cite this paper: Angèle, A.K., Gaël, A., Dégbo, D.M., Anthelme, A.K., Morel, S.Y., Ghislain, M.M.S., Géoffroy, F.A.A., Marcel, Z.D. and Fabien, H. (2021) Factors Associated with High Blood Pressure in People Living with HIV at the National Teaching Hospital Hubert Koutoukou Maga and Cotonou Teaching Hospital of the Armed Forces. Open Journal of Internal Medicine, 11, 283-297.

https://doi.org/10.4236/ojim.2021.114025

Received: November 16, 2021

Accepted: December 28, 2021

Published: December 31, 2021

Copyright $\odot 2021$ by author(s) and Scientific Research Publishing Inc. This work is licensed under the Creative Commons Attribution International License (CC BY 4.0).

http://creativecommons.org/licenses/by/4.0/

(c) (i) Open Access

\begin{abstract}
In Benin Republic, few data are available on the prevalence and determinants of arterial hypertension (AH) in people living with the human immunodeficiency virus (PLWHA). The present study was conducted in two outpatient treatment centers for PLWHA in Cotonou and was conducted from June 19 to July 04, 2019 with 314 PLWHA. We performed descriptive statistics and logistic regression for the estimates. The prevalence of high blood pressure (HBP) among PLWHA was 41.4\% [CI (95\%): (35.9 - 47)]. In univariate analysis: age, smoking, alcoholism, physical inactivity, family history of hypertension, personal history of diabetes, obesity, and total and LDL (low density lipoprotein) hypercholesterolemia were significantly associated with HBP. No association was found with duration of HIV (human immunodeficiency virus) infection, time to ARV (antiretrovirals) exposure, and treatment regimen. In multivariate analysis, age, sex, smoking, family history of hypertension, and total hypercholesterolemia remained associated with HBP. In conclusion, the prevalence of HBP in PLWHA was very high compared with the results in the general population, and the same risk factors described in the general population were found but with a more marked hypertense potential.
\end{abstract}

\section{Keywords}

High Blood Pressure, HIV, Associated Factors, Cotonou (Benin) 


\section{Introduction}

Survival period of PLWHA has improved considerably after the advent of triple antiretroviral therapy at the end of the 1990s [1]. However, this decrease in the mortality of PLWHA is correlated with the increasing appearance of emerging co-morbidities, including cardiovascular and renal diseases [2]. As in many countries in the West African sub-region, little data is available on cardiovascular co-morbidities of HIV-infected persons in Benin. Yet sub-Saharan Africa remains the region of the world most affected by HIV infection. In 2018, 36.9 million people were living with HIV worldwide, of which 25.7 million were in sub-Saharan Africa (69.65\%) [3]. Among the emerging comorbidities, hypertension (HBP) appears to occupy a prominent place due to a number of factors including: chronic inflammation related to vasculopathies [2] in PLWHA, the high frequency of chronic kidney disease [4] [5] and dyslipidemia [6] in these patients, the permanent stress related to the chronicity of the disease and the stigmatization that HIV-positive people undergo daily [7], without forgetting the direct or indirect adverse effects related to antiretroviral drugs [8]. The word group "high blood pressure" (HBP) seems more appropriate in our context because of the cross-sectional nature of this study, which therefore provides, to a certain extent, indicative information to estimate the prevalence of HBP in this group of patients, while allowing the identification of the factors associated with its occurrence. It also has the merit of proposing approaches to solutions to perpetuate the notable advances in the organization of services offered to PLWHA through better management of blood pressure in these patients. The absence of a previous study on this subject in Benin and the similarity of the methodology with the STEPS: non-communicable diseases risk factors survey using the approach WHO's "STEPSwise" (WHO: World Health Organization) in Benin in 2015 [9], motivated a comparison of our results in the analytical part with those of the said survey, which focused on patients from the general population. The final report of this survey had noted a prevalence of High Blood Pressure (HBP) at $25.9 \%$ in Benin and $32.3 \%$ in Cotonou. In 2014, through a study on metabolic syndrome in people living with HIV under antiretroviral treatment in Porto-Novo (Benin), Adebayo et al. had found a prevalence of $\mathrm{AH}$ of $24.6 \%$ in PLWHA in Porto-Novo (Benin) [10]. However, little is still known about the distribution and determinants of hypertension among PLWHA in Benin.

Currently in Benin, the management of HIV-infected patients is well codified with free medical, biological, and psychosocial care. However, nutritional care and other conditions discovered during treatment, depending on the case, are at the patient's expense. Thus, the high cost of treating hypertension and the related paraclinical tests mean that patients are often helpless and do not follow medical prescriptions and hygienic and dietary advice. All of this only increase mortality related to cardiovascular co-morbidities in PLWHA. This study is therefore strongly motivated by the specificity of the care of PLWHAIV in Benin and by the difficulties encountered daily by the practitioners in charge. 


\section{Data and Methods}

\subsection{Study Population}

The study population is about adult patients living with HIV who were being followed in one of the two study centers: the National Reference Center for Research and Care (CNRRPEC) of the Hubert Koutoukou Maga Teaching Hospital (NTHC-HKM) and the Outpatient Treatment Center (CTA) for PLWHA at the Teaching Hospital of the Armed Forces (HIA-CHU). These two centers were chosen for their large and diversified active files, as well as for their geographical proximity facilitating the organizational aspect of the study. To be included in the study, patients had to be between 18 and 69 years of age (with reference to the 2015 STEPS/Benin survey), on antiretroviral therapy (ART) for at least 6 months, seen in routine consultation during the study period, and in full physical and mental capacity. Informed consent was required to participate in the study. Pregnant women and bedridden subjects were excluded.

\subsection{Methods}

This is a descriptive, analytic cross-sectional study that was conducted from June 19 to July 04, 2019. EAP was defined as a BP (Blood Pressure) elevation greater than $140 / 90 \mathrm{mmHg}$ on the day of collection, with persistence of this elevation with resumption of BP after a 15-minute rest period in a sitting position. In addition, patients already reported as hypertensive (history of hypertension), and on specified antihypertensive treatment, were considered positive cases. Global obesity was defined as a body mass index (BMI) greater than $30 \mathrm{~kg} / \mathrm{m}^{2}$. In accordance with the National Cholesterol Education Program III (NCEPIII) criteria [11], the threshold for diagnosis of abdominal obesity was a waist circumference $>102 \mathrm{~cm}$ in men, and $>88 \mathrm{~cm}$ in women. The lipid profile was taken from the patients on the day of data collection. Total hypercholesterolemia was defined as a blood level greater than $2 \mathrm{~g} / \mathrm{L}$, LDL hypercholesterolemia as a level greater than $1 \mathrm{~g} / \mathrm{L}$, and HDL hypocholesterolemia as a level less than $0.5 \mathrm{~g} / \mathrm{L}$ in women and $0.4 \mathrm{~g} / \mathrm{L}$ in men. Hypertriglyceridemia was defined as a blood level above $1.5 \mathrm{~g} / \mathrm{L}$.

Data collection was done daily, simultaneously at the two sites selected, from Monday to Friday, from 8:00 am until the end of the consultations. After obtaining the informed consent of the patients, the different items of the questionnaire were completed as the consultation progressed. Data on HIV infection, CD4 (cluster of differentiation 4) lymphocytes Tcount, and antiretrovirals were obtained from the medical records. On the basis of the information contained in the patient's medical records, we have defined three categories of failure by referring to the national guidelines for standards and procedures in Benin:

Immunological failure corresponded to a $\mathrm{CD} 4$ count becoming equal to or lower than the baseline, or the persistence of a CD4 count of less than 100 cells $/ \mathrm{mm}^{3}$ after 6 months of effective and well-monintoring ART (Antiretroviral therapy) or a drop in CD4 50\% from the peak. 
Virological failure was defined by the persistence after 6 months of well-followed ART, of plasma viral load greater than 1000 copies $/ \mathrm{ml}$ on the basis of two measurements taken 3 months apart during which compliance were reinforced.

Clinical failure was suggested when a new or recurrent clinical event occurs indicating advanced or severe immunodepression, corresponding to WHO clinical stage 3 or 4 .

At the end of the interview, a systematic measurement of BP was performed using an Omron Basic M3 electronic blood pressure monitor. In patients whose numbers were elevated compared with normal, blood pressure was taken again after 15 minutes of rest in a sitting position. Other clinical parameters (weight, height, waist circumference) were also recorded. The physician examined the patient as during routine consultations. At the end of each consultation, the patient was directed to the sampling room, where he or she was given a free sample for the lipid test. LDL cholesterol was subsequently calculated by the Friedewald formula.

Data were entered using EpiData software. Data cleaning and analysis were performed using the statistical software $\mathrm{R}$ version 3.5.1. A descriptive analysis of the variables under study was performed. Thus, for the qualitative variables, the frequencies and proportions were determined in percentages with their confidence intervals (CI). Comparisons were made using the chi2 test or the Fisher exact test if any frequency was less than 5 . For quantitative variables, the means with their standard deviation, medians, minima, and maxima were described. We also computed logistic regression and odds ratios (OR).

\subsection{Ethical Considerations}

The authorization of the ethical council was taken and the confidentiality of the data was guaranteed for each patient as well as their informed consent.

\section{Results}

\subsection{Socio-Demographic, Anthropometric, and Clinical Characteristics of Participants}

Over 365 patients in consultation, 314 were included in the study, of which 263 (84\%) were seen at the CNRRPEC and $51(16 \%)$ at the HIA-CHU. The mean age of the recruited PLWHA was $43.8 \pm 9.30$ years with a minimum of 20 and a maximum of 68 years. Patients between 30 and 50 years of age predominated in our study $(40.1 \%)$. The female sex was the most represented with a predominance of $73.6 \%$, i.e. a sex ratio of 0.34 . More than half of the patients were living with a partner $(55.7 \%)$. A family history of hypertension was found in $31.5 \%$ of the patients, $17.52 \%$ of the patients were already known to be hypertensive (under anti-HTA treatment), and $1.91 \%$ of the patients in our study population had a history of diabetes. $4.78 \%$ of patients were smokers, $4.5 \%$ of patients were alcoholics, and $80.89 \%$ had a sedentary lifestyle $(74.7 \%$ in men and $83.12 \%$ in 
women). Almost one-third (29.62\%) of the patients were abdominally obese with a mean waist circumference of $85.49 \mathrm{~cm}$ in men and $85.42 \mathrm{~cm}$ in women.

The mean BMI was 23.26 with a minimum of 13.34 and a maximum of 42.46 . Approximately 1 in 7 patients was globally obese and $21.66 \%$ of the subjects surveyed were at least overweight.

The prevalence of dyslipidemia was $43.95 \%$ and the lipid profile of the participants was dominated by total hypercholesterolemia (37.3\%).

The socio-demographic and anthropometric characteristics of the study participants are presented in Table 1.

No correlation was found between EAP and characteristics related to HIV infection (Duration of HIV infection, duration of ARVs exposure, Virological failure status, Immunological failure status, and clinical failure status). Furthermore, a cross-referencing of the PAE for each molecule and then each combination of ARVs was performed without obtaining a statistically significant correlation. The mean duration of HIV infection was $8.05 \pm 4.78$ years with a minimum of 1 and a maximum of 19 years. The mean duration of exposure to ARVs was $7.76 \pm 4.71$ years with extremes ranging from 6 months to 17.63 years.

In addition, we have inserted in Table 2 the characteristics related to HIV infection and lipid profile of the patients in the study.

In terms of antiretroviral molecules, the Tenolam-Efavirenz combination was the most widely used (49\%) (Figure 1).

The prevalence of EAP was 41.4\% [CI (95\%): (35.9 - 47)] (130 of 314). It was $42.20 \%$ at the CNRRPEC and $37.25 \%$ at the HIA CTA. As shown in Figure 2, only $17.5 \%$ of patients knew they were already hypertensive at the time of the survey. EAP was newly identified in $23.9 \%$ of the study population who did not have self-reported hypertension before the BP measurement during collection.

\subsection{Associated Factors}

Regarding the associated factors, in univariate analysis, neither gender, collection site, nor level were related to EAP in our cohort. We note a significant positive linear trend in the odds ratio $(\mathrm{OR})$ with age $(\mathrm{P}<0.001)$. The prevalence of EAP was $23.8 \%$ in subjects younger than 30 years, $36.4 \%$ in those aged 30 to 50 years, and $62.17 \%$ in those older than 50 years, respectively (Table 1). The risk of having an EAP was increased by 2.35 -fold in patients with a family history of hypertension $(\mathrm{OR}=2.35 ; 95 \% \mathrm{CI}[1.43$ - 3.87]; $\mathrm{P}=0.02$ '). A personal history of diabetes increased the risk of developing EAP by a factor of $7.32(\mathrm{OR}=7.32$; 95\% CI [0.84-63.41]; P $=0.03$ '). A sedentary lifestyle appeared to increase the risk of developing an EAP by a factor of 1.67 , but this association was not very significant $(\mathrm{OR}=1.67 ; 95 \% \mathrm{CI}[0.92-3.04] ; \mathrm{P}=0.05$ '). Tobacco use appeared to increase the risk of developing EAP by a factor of 4.12 (OR $=4.12$; 95\% CI [1.37 15.06]; $\mathrm{P}=0.02$ '); alcohol use appeared to almost double the risk $(\mathrm{OR}=1.70$; $95 \%$ CI [1.07 - 2.74]; $\left.\mathrm{P}=0.03^{\prime}\right)$. Overall, obesity appeared to increase the risk of developing EAP by 2.88 -fold ( $\mathrm{OR}=2.88$; $95 \%$ CI $[1.49-5.59$ ]; $\mathrm{P}=0.02$ '). Abdominal obesity was strongly associated with the risk of developing EAP and 
Table 1. Socio-demographic, anthropometric, and clinical characteristics of participants.

\begin{tabular}{|c|c|c|c|c|c|c|}
\hline Variables & \multicolumn{2}{|c|}{ HBP-Yes } & \multicolumn{2}{|c|}{ HBP-No } & $\mathrm{OR}^{9}\left[\mathrm{IC}^{\ddagger}(95 \%)\right]$ & $\mathrm{P}$-value \\
\hline CNRRPEC & 111 & $(35.35 \%)$ & 152 & $(48.41 \%)$ & 1 & 0.512 \\
\hline HIA & 19 & $(6.05 \%)$ & 32 & $(10.19 \%)$ & $0.81[0.44-1.51]$ & \\
\hline \multicolumn{7}{|l|}{ Gender } \\
\hline Female & 90 & $(28.66 \%)$ & 141 & $(44.90 \%)$ & 1 & 0.086 \\
\hline Male & 41 & $(13.06 \%)$ & 42 & $(13.38 \%)$ & $1.53[0.94-2.58]$ & \\
\hline \multicolumn{7}{|l|}{ Age } \\
\hline$<30$ & 5 & $(1.59 \%)$ & 16 & $(5.10 \%)$ & 1 & \multirow{3}{*}{$<0.001^{*}$} \\
\hline$[30-50]$ & 79 & $(25.16 \%)$ & 138 & $(43.95 \%)$ & $1.83[0.65$ - 5.19] & \\
\hline$>50$ & 46 & $(14.65 \%)$ & 30 & $(9.55 \%)$ & $5.26[1.73-15.93]$ & \\
\hline \multicolumn{7}{|l|}{ Education } \\
\hline No & 30 & $(9.55 \%)$ & 46 & $(14.65 \%)$ & 1 & \multirow[t]{2}{*}{0.695} \\
\hline Yes & 100 & $(31.85 \%)$ & 138 & $(43.95 \%)$ & $1.11[0.66-1.88]$ & \\
\hline \multicolumn{7}{|l|}{ Profession } \\
\hline No job & 22 & $(7.01 \%)$ & 23 & $(7.32 \%)$ & 1 & \multirow{3}{*}{0.154} \\
\hline Civil servant & 8 & $(2.55 \%)$ & 5 & $(1.59 \%)$ & $1.67[0.47-5.9]$ & \\
\hline Private sector & 100 & $(31.85 \%)$ & 156 & $(49.68 \%)$ & $0.67[0.35-1.27]$ & \\
\hline \multicolumn{7}{|l|}{ Marital status } \\
\hline Single & 13 & $(4.14 \%)$ & 16 & $(5.09 \%)$ & 1 & \multirow{3}{*}{0.59} \\
\hline In couple & 68 & $(21.66 \%)$ & 107 & $(34.08 \%)$ & $0.78[0.35-1.73]$ & \\
\hline Separated & 49 & $(15.60 \%)$ & 61 & $(19.43 \%)$ & $0.98[0.43-2.25]$ & \\
\hline \multicolumn{7}{|l|}{ Family history of HBP } \\
\hline No & 66 & $(21.02 \%$ & 124 & $(39.49 \%)$ & 1 & \multirow[t]{2}{*}{$0.02^{*}$} \\
\hline Yes & 55 & $(17.52 \%$ & 44 & $(14.01 \%)$ & $2.35[1.43-3.87]$ & \\
\hline \multicolumn{7}{|c|}{ Personal history of diabetes } \\
\hline No & 125 & $(39.81 \%)$ & 183 & $(58.28 \%)$ & 1 & \multirow[t]{2}{*}{$0.03^{*}$} \\
\hline Yes & 5 & $(1.59 \%)$ & 1 & $(0.32 \%)$ & $7.32[0.84-63.41]$ & \\
\hline \multicolumn{7}{|l|}{ Sedentary lifestyle } \\
\hline No & 19 & $(6.05 \%)$ & 41 & $(13.06 \%)$ & 1 & \multirow[t]{2}{*}{$0.05^{*}$} \\
\hline Yes & 111 & $(35.35 \%)$ & 43 & $(13.69 \%)$ & $1.67[0.84-3.04]$ & \\
\hline \multicolumn{7}{|l|}{ Smoking } \\
\hline No & 120 & $(38.22 \%)$ & 179 & $(57.01 \%)$ & 1 & \multirow[t]{2}{*}{$0.02^{*}$} \\
\hline Yes & 10 & $(3.18 \%)$ & 5 & $(1.59 \%)$ & $4.12[1.37-15.06]$ & \\
\hline \multicolumn{7}{|l|}{ Alcoholism } \\
\hline No & 40 & $(12.74 \%)$ & 81 & $(25.80 \%)$ & 1 & \multirow[t]{2}{*}{$0.03^{*}$} \\
\hline Yes & 90 & $(28.66 \%)$ & 103 & $(32.80 \%)$ & $1.70[1.07-2.74]$ & \\
\hline Overall obesity & & & & & & \\
\hline No & 102 & $(32.48 \%)$ & 168 & $(53.50 \%)$ & 1 & $0.02^{*}$ \\
\hline Yes & 28 & $(8.92 \%)$ & 16 & $(5.10 \%)$ & 2.88 [1.49 - 5.59] & \\
\hline Abdominal obesity & & & & & & \\
\hline No & 71 & $(22.61 \%)$ & 150 & $(47.77 \%)$ & 1 & $<0.001^{*}$ \\
\hline Yes & 59 & $(18.79 \%)$ & 34 & $(10.83 \%)$ & $3.67[2.21-6.09]$ & \\
\hline
\end{tabular}


Table 2. Characteristics related to HIV infection and lipid profile of patients.

\begin{tabular}{|c|c|c|c|c|c|c|}
\hline \multirow{2}{*}{$\begin{array}{c}\text { Variables } \\
\text { Duration of HIV }\end{array}$} & \multicolumn{2}{|c|}{ HBP-Yes } & \multicolumn{2}{|c|}{ HBP-No } & $\mathrm{OR}^{g}\left[\mathrm{IC}^{\ddagger}(95 \%)\right]$ & $\mathrm{P}$-value \\
\hline & & & & & & \\
\hline$<5$ years & 45 & $(14.33 \%)$ & 72 & $(22.93 \%)$ & 1 & \\
\hline$[5-10[$ years & 37 & $(11.78 \%)$ & 56 & $(17.84 \%)$ & $1.05[0.61-1.84]$ & 0.617 \\
\hline $10-15[$ years & 39 & $(12.42 \%)$ & 43 & $(13.69 \%)$ & $1.10[0.80-2.57]$ & \\
\hline$\geq 15$ years & 9 & $(2.87 \%)$ & 13 & $(4.14 \%)$ & $1.85[0.43-2.80]$ & \\
\hline \multicolumn{7}{|c|}{ Duration of ARVs exposure } \\
\hline$<5$ years & 42 & $(13.38 \%)$ & 67 & $(21.34 \%)$ & 1 & \\
\hline$[5-10[$ years & 38 & $(12.10 \%)$ & 58 & $(18.47 \%)$ & $1.04[0.60-1.83]$ & 0.201 \\
\hline $10-15[$ years & 38 & $(12.10 \%)$ & 45 & $(14.33 \%)$ & $1.34[0.75-2.40]$ & \\
\hline$\geq 15$ years & 12 & $(3.82 \%)$ & 14 & $(4.46 \%)$ & $1.36[0.58-3.24]$ & \\
\hline \multicolumn{7}{|c|}{ Virological failure status } \\
\hline No & 112 & $(35.67 \%)$ & 163 & $(51.91 \%)$ & 1 & 0.463 \\
\hline Yes & 18 & $(5.73 \%)$ & 21 & $(6.69 \%)$ & $1.37[0.69-2.74]$ & \\
\hline \multicolumn{7}{|c|}{ Immunological failure status } \\
\hline No & 114 & $(36.31 \%)$ & 163 & $(51.91 \%)$ & 1 & 0.982 \\
\hline Yes & 16 & $(5.09 \%)$ & 21 & $(6.69 \%)$ & $1.07[0.53-2.13]$ & \\
\hline \multicolumn{7}{|c|}{ Clinical failure status } \\
\hline No & 126 & $(40.13 \%)$ & 180 & $(57.33 \%)$ & 1 & 0.723 \\
\hline Yes & 4 & $(1.27 \%)$ & 4 & $(1.27 \%)$ & $1.41[0.33-6.06]$ & \\
\hline \multicolumn{7}{|l|}{ Dyslipidemia } \\
\hline No & 59 & $(18.79 \%)$ & 117 & $(37.26 \%)$ & 1 & 0.01 \\
\hline Yes & 71 & $(22.61 \%)$ & 67 & $(21.34 \%)$ & $1.1[0.76-1.48]$ & \\
\hline \multicolumn{7}{|c|}{ Total Hypercholesterolemia } \\
\hline No & 65 & $(20.70 \%)$ & 132 & $(42.04 \%)$ & 1 & $<0.001^{*}$ \\
\hline Yes & 65 & $(20.70 \%)$ & 52 & $(16.56 \%)$ & $2.54[1.59-4.06]$ & \\
\hline \multicolumn{7}{|c|}{ LDL hypercholesterolemia } \\
\hline No & 109 & $(34.71 \%)$ & 169 & $(53.82 \%)$ & 1 & $0.03^{*}$ \\
\hline Yes & 21 & $(6.69 \%)$ & 15 & $(4.78 \%)$ & $1.4[0.72-2.72]$ & \\
\hline \multicolumn{7}{|c|}{ HDL hypocholesterolemia } \\
\hline No & 125 & $(39.81 \%)$ & 173 & $(55.10 \%)$ & 1 & 0.40 \\
\hline Yes & 5 & $(1.59 \%)$ & 11 & $(3.50 \%)$ & $0.45[0.15-1.30]$ & \\
\hline \multicolumn{7}{|c|}{ Hypertriglyceridemia } \\
\hline No & 115 & $(36.62 \%)$ & 173 & $(55.10 \%)$ & 1 & 0.083 \\
\hline Yes & 15 & $(4.78 \%)$ & 11 & $(3.50 \%)$ & $1.36[0.62-2.97]$ & \\
\hline
\end{tabular}

HDL: High density lipoprotein, LDL: Low density lipoprotein. 

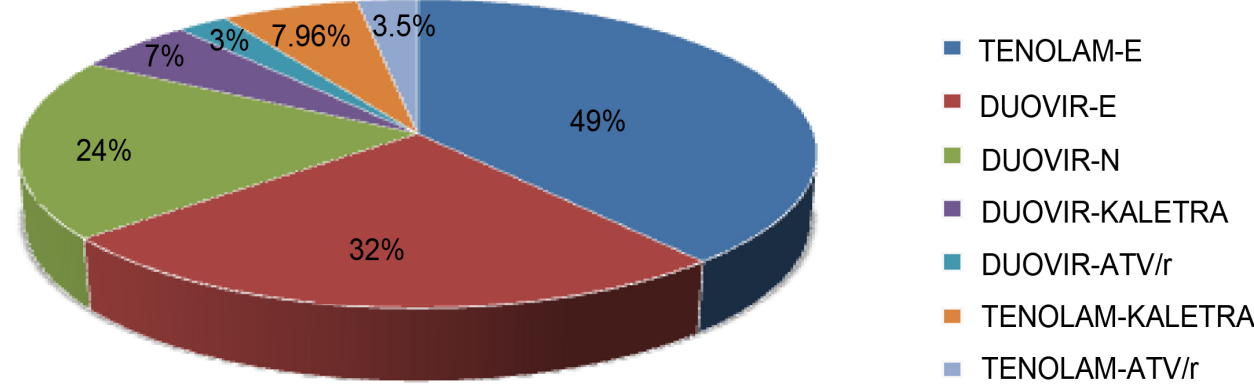

Figure 1. Distribution of study patients by commonly used ARV combinations. TENOLAM-E: Ténofovir-Lamivudine-Efavirenz; DUOVIR-E: Zidovudine-Lamivudine-Efavirenz; DUOVIR-N: Zidovudine-Lamivudine-Névirapine; DUOVIR-KALETRA: Zidovudine-Lamivudine-Lopinavir boosté par le Ritonavir; DUOVIR-ATV/r: Zidovudine-Lamivudine-Atazanir boosté par le ritonavir; TENOLAM-KALETRA: Ténofovir-Lamivudine-Lopinavir boosté par le Ritonavir; TENOLAM-ATV/r: Ténofovir-Lamivudine-Atazanir boosté par le ritonavir.

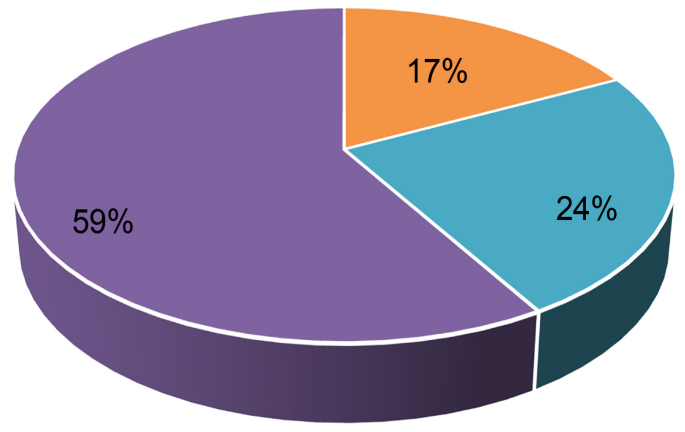

\author{
PLWHA with EAP \\ - PLWHA with a known \\ history of hypertension \\ - PLWHA with newly \\ detected hypertension
}

Figure 2. Prevalence of EAP and distribution of patients at the time of discovery.

appeared to increase it by about 4 times ( $\mathrm{OR}=3.67$; 95\% CI [2.21 - 6.09]; $\mathrm{P}<$ $\left.0.001^{\prime}\right)$. We did not find an association between the duration of HIV infection and the development of EAP (Table 2).

In multivariate analysis, age, sex, family history of hypertension, smoking, abdominal obesity, and total hypercholesterolemia were significantly associated with EAP. Male subjects had twice the risk of developing EAP compared with female subjects, adjusted for age, family history of hypertension, smoking, abdominal obesity, and total hypercholesterolemia (Table 3).

\title{
4. Discussion
}

In this study, we found a high prevalence of EAP of $41.4 \%$ [95\% CI: (35.9 - 47)] among HIV-infected persons. One of the goals of this study was to identify factors associated with EAP, whether or not they were inherent to ART. Thus, in the absence of a control population consisting of ART-naive HIV-positive patients, we took as a reference an HIV-negative population provided by a national survey conducted by WHO in 2015 on the surveillance of risk factors for non-communicable diseases (25.9\%) in Benin (STEPS 2015/Benin) [9]. The prevalence of $41.4 \%$ is much higher than that obtained in the general population in Benin in 2015 by the STPEPS 2015 survey (25.9\%), as well as that obtained in 
a purely urban population in Cotonou in 2015 through the same survey (32.3\%).

It is however, identical to that of Magalhaes et al. in Brazil in 2007 (41.4\%) [12], and close to the findings of Menanga et al. in 2015 [13], and Dimala et al. in 2016 [14] in Cameroon, which noted respectively prevalence of: $43.2 \%$ and $38 \%$. Through a published 20-year retrospective study, Benzekri et al. [15] had already made findings strongly suggesting an insufficient diagnosis of hypertension. They reported in 2018 that in 20 years, the prevalence of hypertension had doubled in HIV-positive and HIV-negative individuals, however, the high prevalence of hypertension found by these studies is not sufficient to affirm with certainty that the prevalence of hypertension is greater in HIV-positive populations, as the conclusions of previous studies are not all unanimous on the preponderance of hypertension in PLWH. Thus, Gazzaruso et al. [16] found an increased prevalence of hypertension (34.2\% versus $11.9 \%)$ in patients on HAART, in contrast to Bergensen et al. [17] who found no association. In addition, one of the findings of this study is that very few hypertensive patients actually know their hypertension status. This remark is in cohesion with the work of Houinato et al. [18] in Benin who reported in 2012 that only one hypertensive person out of four knew he was hypertensive with a prevalence of hypertension of $27.9 \%$.

Only age was significantly associated with EAP $(\mathrm{P}<0.001)$ (Table 1$)$. The older is the age of the subject, the greater is the risk of developing EAP. Older age, particularly over 50 years, is a key factor in the development of HBP. This increase in the risk of developing hypertension, especially after 50 years of age, is probably related to the increase in arterial stiffness that occurs with age, which is itself aggravated by other risk factors already present, such as obesity, dyslipidemia and sedentary lifestyle [19]. The risk of developing hypertension was seven times higher in diabetic subjects $(\mathrm{P}=0.03)$ ('Table 1 ). This finding is consistent with the conclusions of Houétondji et al. [20] in 2016 who found a prevalence of hypertension of $60 \%$ in HIV-negative diabetic subjects in Parakou (Benin). Indeed, overweight, arterial stiffness, and nephropathy are often present in diabetic subjects (T2+) are factors predisposing them to develop hypertension more frequently. This corroborates the strong interrelationships between obesity, T2DM, and hypertension. However, diabetes is much less prevalent than hypertension with a prevalence of $1.91 \%$ in the study population, half the prevalence of diabetes in the general population in Benin in 2012 (3.2\%) [18].

Patients with a family history of hypertension had a 2.35-fold increased risk of hypertension ( $\mathrm{p}=0.02$ ) (Table 1$)$. In multivariate analysis, this risk was increased, with the prevalence ratio rising to $3.22(\mathrm{P}<0.001)$ (Table 3 ). This association has also been reported by Cunha et al. in 2018 [21]. The risk of having an EAP was increased in alcoholic patients with $\mathrm{OR}=1.70[0.72-2.72]$; the same was true for smoking patients $(\mathrm{P}=0.02)$. There was a correlation between EAP and physical inactivity, the latter increasing the risk of EAP by 1.67 [95\% CI: $(0.92-3.04)]$. Four out of five $(80.89 \%)$ of the PLWH did not even engage in physical activity at least once a week, and this finding was similar in both sexes. 
Table 3. Final modeling of the relationship between EAP and associated factors.

\begin{tabular}{|c|c|c|c|c|}
\hline & \multicolumn{2}{|c|}{ Univariate Analysis } & \multicolumn{2}{|c|}{ Multivariate Analysis } \\
\hline & Brut OR [CI 95\%] & p-value & Ajusted OR [CI 95\%] & $\mathrm{P}$-value \\
\hline Age & & $<0.001$ & & $<0.001^{*}$ \\
\hline$\leq 30$ years & 1 & & 1 & \\
\hline$[30-50]$ years & $2.06[0.74-5.76]$ & & $1.6[0.54-4.78]$ & \\
\hline$>50$ years & $5.91[1.98-17.71]$ & & $5.14[1.59-16.66]$ & \\
\hline Sex & & & & $0.021^{*}$ \\
\hline Female & 1 & & 1 & \\
\hline Male & $1.56[0.94-2.58]$ & & $2.15[1.12-4.11]$ & \\
\hline Family history of HBP & & 0.002 & & $<0.001^{*}$ \\
\hline No & 1 & & 1 & \\
\hline Yes & $2.40[1.46-3.95]$ & & $3.22[1.82-5.69]$ & \\
\hline Smoking & & $<0.02$ & & $0.014^{*}$ \\
\hline No & 1 & & 1 & \\
\hline Yes & $4.16[1.29-13.377]$ & & $4.83[1.29-18.12]$ & \\
\hline Abdominal obesity & & $<0.001$ & & $<0.001^{*}$ \\
\hline No & 1 & & 1 & \\
\hline Yes & $3.67[2.21-6.09]$ & & $4.88[2.63-9.05]$ & \\
\hline Total hypercholesterolemia & & $<0.001$ & & 0.116 \\
\hline No & 1 & & 1 & \\
\hline Yes & $2.54[1.59-4.06]$ & & $1.56[0.9-0.71]$ & \\
\hline
\end{tabular}

The large difference in the prevalence of sedentary lifestyle between the STEPS survey and the present study (16\% versus $80.89 \%$ ) highlights a serious lack of physical activity in the PLWHIV population. This could be explained by the feeling of chronic asthenia reported by many HIV positive subjects [22]. The prescription of physical activity should therefore be discussed taking into account the assessment of the overall cardiovascular risk and nutritional status to promote good compliance and a lasting change in lifestyle.

Obese subjects $\left(\mathrm{BMI} \geq 30 \mathrm{Kg} / \mathrm{m}^{2}\right)$ were 2.88 times more likely to have an EAP $(\mathrm{p}=0.02)$. These results are superimposed on those of Signorini et al. [23] in 2012 in Brazil who reported that the risk of developing PAE was increased by more than two times in subjects with a BMI $\geq 25 \mathrm{Kg} / \mathrm{m}^{2}$. Moreover, the average BMI of $23.26 \mathrm{Kg} / \mathrm{m}^{2}$ found in this study is similar to that found in the STEPS 2015 survey $\left(23.2 \mathrm{Kg} / \mathrm{m}^{2}\right)$ [9] but the prevalence of obesity is slightly higher $(14 \%$ versus $10 \%$ ). This is another argument in favor of the increasing tendency of PLWHA on ART to gain weight, the latter being considered as an element of monitoring therapeutic compliance; but this weight gain seems to expose them more to developing hypertension. Regarding abdominal obesity, it was closely 
associated with EAP, increasing the risk by 3.67 -fold $(\mathrm{P}<0.001)$. The mean waist circumference of participants was $85.49 \mathrm{~cm}$ in men and $85.42 \mathrm{~cm}$ in women compared with 79.4 and 81.5, respectively, in the 2015 STEPS survey. This denotes an increasingly frequent reversal of the weight status of PLWHA through the loss of emaciation that used to characterize them, with the corollary of an explosion in the prevalence of cardiovascular disease in these patients [6] [10] [24]. These factors (increase in BMI and waist circumference) therefore seem to play a determining role in the genesis of hypertension in PLWHA on ART.

The prevalence of hypertension was significantly elevated in PLWH with dyslipidemia $(P=0.01)$ (Table 2$)$. In univariate analysis, this association was particularly notable in patients with total hypercholesterolemia $(\mathrm{P}<0.001)$ and those with elevated LDL cholesterol $(P=0.03)$ (Table 2). Dyslipidemias are strong predictors of hypertension in the general population; the results of this study provide evidence that the same is true in HIV-infected patients. Bergersen et al. [17] also reported a positive correlation between hypertension and hypercholesterolemia and hypertriglyceridemia. The same was true for the study of Arruda et al. [25] who noted a multiplication of the risk of hypertension by 1.51 and 2.52, respectively, in case of total hypercholesterolemia or hypertriglyceridemia. The prevalence of dyslipidemia of $43.9 \%$ is lower than that obtained by Zannou et al. [6] in 2014 which was 59\%, but the lipid profiles of the participants in these two studies, are superimposable with a dominance of total hypercholesterolemia. At the end of this study, no association between ART-related characteristics and EAP was established, whether it was duration of infection, duration of exposure to ARVs or situations of virological, immunological or clinical failure (Table 2). Numerous studies similar to ours, carried out in different countries, have not found an association between HBP and data on antiretroviral treatment [10] [15] [17] [26] [27] [28]. On the other hand, Baekken et al. [29] in Norway in 2008 noted a higher prevalence of hypertension in patients treated with a combination of antiretroviral drugs for more than 5 years $(44.4 \%$ versus $36.5 \%$ in the sample), suggesting an increase in the prevalence of hypertension in PLWH exposed to ARVs for a longer period. Similarly, Arruda et al. in Brazil in 2010 [25] found an association between the duration of antiretroviral treatment and the number of CD4 $>200$ cells $/ \mathrm{mm}^{3}$ and $\mathrm{HAH}$.

The ideal way to study the effect of ART on the BP of the patients surveyed would therefore have been to carry out a case-control study on two groups of PLWHA (with and without ART). However, with the systematic placing of all diagnosed PLWH on ART, this study is no longer feasible. In addition, the viral load of each patient could not be measured in this study, which could have contributed to a better understanding of the pathophysiological mechanisms of hypertension in HIV-infected persons. Despite this shortcoming, this study adds to the scarce existing information specifically on HIV and hypertension in sub-Saharan Africa in general and in Benin in particular. As limitations, ideally, it would have been possible to conduct a cohort study with groups of 
HIV-positive (with and without ARVs) and HIV-negative subjects. However, it is not the case in this work. Furthermore, not measuring the CD4 count at the time of collection in order to have a more recent CD4 count and better study the possible risk of EAP according to the $\mathrm{CD} 4$ level.

\section{Conclusions}

To determine the prevalence of high blood pressure and associated factors among PLWHIV in two outpatient care centers in Cotonou, we conducted a descriptive and analytical cross-sectional study. This led to the following results: In total, the prevalence of EAP among PLWHIV was $41.4 \%$. In univariate analysis, an association was found with traditional risk factors for hypertension. These included: older age, smoking, alcoholism, physical inactivity, family history of hypertension, personal history of diabetes, abdominal obesity, global obesity, and total and LDL hypercholesterolemia. No association was found with duration of antiretroviral therapy, time to ARV exposure, and regimen. Multivariate analysis included the following predictive factors: age, sex, smoking, family history of hypertension, and total hypercholesterolemia.

Our study shows that the prevalence of EAP is high among HIV-infected persons in Cotonou. The factors associated with this EAP are mostly modifiable. The prevention of HAE in PLWH should integrate the control of these factors. Our results provide further evidence of the preponderance of HAE in PLWH and underscore the importance of analyzing the effect of antiretroviral therapy. In Benin, treatment of HIV-infected patients is provided by the government. Thus, the evidence found in our study could be useful to propose new guidelines for the management of metabolic disorders (dyslipidemia, diabetes, obesity) during the follow-up of PLWH.

\section{Conflicts of Interest}

The authors declare no conflicts of interest regarding the publication of this paper.

\section{References}

[1] The New Humanitarian (2003) Une brève histoire d'antirétroviraux. Johannersburg.

https://www.thenewhumanitarian.org/fr/report/42444/afrique-une-br\%C3\%A8ve-h istoire-d\%E2\%80\%99anti\%C3\%A9troviraux

[2] Zannou, D., Tchabi, Y., Ahomadégbé, C., Akakpo, J., Azon Kouanou, A., Adè, G., et al. (2013) Risque cardiovasculaire chez les personnes vivant avec le VIH à l'hopital universitaire de Cotonou, Bénin. Médecine d’ Afrique Noire, 60, 419-426.

[3] Aubry, P.P. and Gausere, D.B.-A. (2019) Infection par le VIH/Sida et tropiques. Centre René Labusquière, Institut de Médecine Tropicale, Université de Bordeaux, Bordeaux, 20 p. http://medecinetropicale.free.fr/sida tropical.pdf

[4] Bognounou, R., Diendéré, A., Diallo, I., Tieno, H., Guira, O., Ouedraogo, D.D., et al. (2011) Metabolic Disorders and Cardiovascular Risk Factors Observed in $\mathrm{Pa}$ - 
tients Infected by the HIV with Antiretroviral Therapy in Burkina Faso. Tropical Medicine, 71, 626-627.

[5] Houngbe, C. (2013) Prévalence de l'insuffisance rénale et facteurs associés chez les patients traités par les antirétroviraux au CNHU-HKM. Thèse de Médecine No. 1632, Faculté des sciences se santé de Cotonou, Cotonou.

[6] Zannou, D.M. and Gansou, N. (2014) Les dyslipidémies: Prévalence et facteurs associés chez les sujets infectés au VIH à l'hôpital universitaire Hubert K. MAGA de Cotonou. Faculté de Sciences de la Santé (FSS) de Cotonou/Université d’Abomey-Calavi (UAC), Cotonou.

[7] Earnshaw, V.A., Lang, S.M., Lippitt, M., Jin, H. ans Chaudoir, S.R. (2015) HIV Stigma and Physical Health Symptoms: Do Social Support, Adaptive Coping, and/or Identity Centrality Act as Resilience Resources? AIDS and Behavior, 19, 41-49. https://doi.org/10.1007/s10461-014-0758-3

[8] Zannou, D.M. and Fatindé, N. (2017) Evaluation a long terme du traitement antirétroviral deuxième ligne dans un centre de référence à Cotonou. Faculté de Sciences de la Santé (FSS) de Cotonou/Université d'Abomey-Calavi (UAC), Cotonou.

[9] World Health Organization (2015) Rapport final de l'enquête pour la surveillance des facteurs de risque des maladies non transmissibles par l'approche "STEPSwise" de l'OMS ENQUETE 'STEPS 2015” au Bénin.pdf. https://www.who.int/ncds/surveillance/steps/Benin 2015 STEPS Report FR.pdf

[10] Adébayo, A., Albert, D.C., Ericie, S., Angelo, A.C., Jules, G., Armand, W., et al. (2015) Prévalence, facteurs associés et prédisposant au syndrome métabolique chez les personnes vivants avec le VIH sous traitement antirétroviral à Porto-Novo en 2014. Pan African Medical Journal, 22, Article No. 296.

https://doi.org/10.11604/pamj.2015.22.296.7923

https://www.ncbi.nlm.nih.gov/pmc/articles/PMC4769044/

[11] National Cholesterol Education Program (NCEP) Expert Panel on Detection, Evaluation and Treatment of High Blood Cholesterol in Adults (Adult Treatment Panel III) (2002) Third Report of the National Cholesterol Education Program (NCEP) Expert Panel on Detection, Evaluation, and Treatment of High Blood Cholesterol in Adults (Adult Treatment Panel III) Final Report. Circulation, 106, 3143-3421. https://doi.org/10.1161/circ.106.25.3143

[12] Magalhães, M.G., Greenberg, B., Hansen, H. and Glick, M. (2007) Comorbidities in Older Patients with HIV: A Retrospective Study. Journal of the American Dental Association, 138, 1468-1475. https://doi.org/10.14219/jada.archive.2007.0083

[13] Menanga, A.P., Ngomseu, C.K., Jingi, A.M., Mfangam, B.M., Noubiap, J.J.N., Gweth, M.N., et al. (2015) Patterns of Cardiovascular Disease in a Group of HIV-Infected Adults in Yaoundé, Cameroon. Cardiovascular Diagnosis and Therapy, 5, 420-427. https://www.ncbi.nlm.nih.gov/pmc/articles/PMC4666691/

[14] Dimala, C.A., Atashili, J., Mbuagbaw, J.C., Wilfred, A. and Monekosso, G.L. (2016) Prevalence of Hypertension in HIV/AIDS Patients on Highly Active Antiretroviral Therapy (HAART) Compared with HAART-Naïve Patients at the Limbe Regional Hospital, Cameroon. PLoS ONE, 11, Article ID: e0148100.

https://doi.org/10.1371/journal.pone.0148100 https://www.ncbi.nlm.nih.gov/pmc/articles/PMC4749660/

[15] Benzekri, N.A., Seydi, M., Doye, I.N., Toure, M., Sy, M.P., Kiviat, N.B., et al. (2018) Increasing Prevalence of Hypertension among HIV-Positive and Negative Adults in Senegal, West Africa, 1994-2015. PLoS ONE, 13, Article ID: e0208635. 
https://doi.org/10.1371/journal.pone.0208635

https://journals.plos.org/plosone/article?id=10.1371/journal.pone.0208635

[16] Gazzaruso, C., Bruno, R., Garzaniti, A., Giordanetti, S., Fratino, P., Sacchi, P., et al. (2003) Hypertension among HIV Patients: Prevalence and Relationships to Insulin Resistance and Metabolic Syndrome. Journal of Hypertension, 21, 1377-1382. https://doi.org/10.1097/00004872-200307000-00028 https://journals.lww.com/jhypertension/Abstract/2003/07000/Hypertension among HIV patients prevalence and.28.aspx

[17] Bergersen, B., Sandvik, L., Dunlop, O., Birkeland, K. and Bruun, J. (2003) Prevalence of Hypertension in HIV-Positive Patients on Highly Active Retroviral Therapy (HAART) Compared with HAART-Naive and HIV-Negative Controls: Results from a Norwegian Study of 721 Patients. European Journal of Clinical Microbiology and Infectious Diseases, 22, 731-736. https://doi.org/10.1007/s10096-003-1034-z

[18] Houinato, D.S., Gbary, A.R., Houehanou, Y.C., Djrolo, F., Amoussou, M., Segnon-Agueh, J., et al. (2012) Prevalence of Hypertension and Associated Risk Factors in Benin. Revue đ’ Épidémiologie et de Santé Publique, 60, 95-102.

https://doi.org/10.1016/j.respe.2011.09.010

[19] DANEL, C.H.H. and Guehi, C.H.H. (2017) Facteurs de risque cardiovasculaire chez les patients avant et après initiation des antirétroviraux en Afrique Sub-Saharienne, expérience de l'Essai Temprano ANRS 12 136. Université de Bordeaux, Bordeaux. http://www.theses.fr/2016BORD0324

[20] Houetondji, H.L.C., Alassani, A., Sonou, D.A., Dohou, S.H., Awassi, B., Adjagba, P.M., et al. (2018) Prévalence de l'hypertension artérielle chez les diabétiques de type 2 suivis en milieu hospitalier à Parakou en 2016. Médecine d Afrique Noire, 65 , $49-58$.

https://bec.uac.bj/uploads/publication/7d8e002336fca4407caa9c13702eb83a.pdf

[21] da Cunha, G.H., Lima, M.A.C., Galvão, M.T.G., Fechine, F.V., Fontenele, M.S.M. andSiqueira, L.R. (2018) Prevalence of Arterial Hypertension and Risk Factors among People with Acquired Immunodeficiency Syndrome. Revista Latino-Americana de Enfermagem, 26, Article No. e3066.

https://doi.org/10.1590/1518-8345.2684.3066

[22] Hoseinean, R. (2012) Élucider la complexité de la fatigue liée au VIH. Nouvelles CATIE.

https://www.catie.ca/fr/nouvellescatie/2012-10-23/elucider-complexite-fatigue-lieevih

[23] Signorini, D.J.H.P., Monteiro, M.C.M., Andrade, M.deF.C.de, Signorini, D.H. and Eyer-Silva, W.de.A. (2012) What Should We Know about Metabolic Syndrome and Lipodystrophy in AIDS? Revista da Associação Médica Brasileira, 58, 70-75.

[24] Rogalska-Płońska, M., Grzeszczuk, A., Rogalski, P., Łucejko, M. and Flisiak, R. (2018) Metabolic Syndrome in HIV Infected Adults in Poland. Kardiologia Polska, 76, 548-553. https://doi.org/10.5603/KP.a2017.0249 https://ojs.kardiologiapolska.pl/kp/article/view/11666

[25] Arruda, L.M., Oliveira, J.M., Cotta Rmm, D.E. and Ribeiro, S.M.R. (2015) Perfil Sociossanitário DE Portadores DE Hipertensão Arterial Cadastrados NA Estratégia DE Saúde DA Família, Divinésia, Minas Gerais. Arquivos, 18. https://periodicos.uff..br/index.php/aps/article/view/15402

[26] Kiama, C.N., Wamicwe, J.N., Oyugi, E.O., Obonyo, M.O., Mungai, J.G., Roka, Z.G., et al. (2018) Prevalence and Factors Associated with Metabolic Syndrome in an Urban Population of Adults Living with HIV in Nairobi, Kenya. Pan African Medical 
Journal, 29, Article No. 90. https://doi.org/10.11604/pamj.2018.29.90.13328 https://www.ncbi.nlm.nih.gov/pmc/articles/PMC5987082/

[27] Malaza, A., Mossong, J., Bärnighausen, T. and Newell, M.-L. (2012) Hypertension and Obesity in Adults Living in a High HIV Prevalence Rural Area in South Africa. PLoS ONE, 7, Article ID: e47761. https://doi.org/10.1371/journal.pone.0047761 https://www.journals.plos.org/plosone/article?id=10.1371/journal.pone.0047761

[28] de la Serna, J.I.B., Zamora, F.X., Montes, M.L., García-Puig, J. and Arribas, J.R. (2010) Hipertensión arterial, infección por el virus de la inmunodeficiencia humana y tratamiento antirretrovírico de gran actividad. Enfermedades Infecciosas y Microbiología Clínica, 28, 32-37. https://doi.org/10.1016/j.eimc.2008.07.005

[29] Baekken, M., Os, I., Sandvik, L. and Oektedalen, O. (2008) Hypertension in an Urban HIV-Positive Population Compared with the General Population: Influence of Combination Antiretroviral Therapy. Journal of Hypertension, 26, 2126-2133. https://doi.org/10.1097/HJH.0b013e32830ef5fb 